\title{
LA GEOMORFOLOGÍA DE LA COLADA DE CERVANTES, VOLCÁN IRAZÚ (COSTA RICA): DESCRIPCIÓN DE UNO DE LOS CAMPOS DE LAVA MÁS GRANDES DE AMÉRICA CENTRAL
}

\author{
THE CERVANTES LAVA FLOW GEOMORFOLOGY, IRAZÚ VOLCANO (COSTA RICA): \\ DESCRIPTION OF THE CENTRALAMERICA`S GREATER LAVA FLOW FIELD
}

\author{
Guillermo E. Alvarado ${ }^{*}$ \& Ana E. Vega ${ }^{2}$ \\ ${ }^{1}$ Área de Amenazas y Auscultación Sísmica y Volcánica, ICE, \\ Apdo. 10032-1000, Costa Rica \\ ${ }^{2}$ Montes de Oca, San José, Costa Rica \\ *Autor para contacto: galvaradoi@ice.go.cr
}

(Recibido: 25/2/2013; aceptado: 11/6//2013)

\begin{abstract}
The Cervantes lava flow field, on the southeastern flank of Irazú volcano, is the most recent and large effusive event dated at this volcano. The Cervantes lava flow actually consists of two different bi-modal lava flow fields. The Western composite lava field $\left(10.85 \mathrm{~km}^{2}, 0.18 \pm 0.1 \mathrm{~km}^{3}\right)$ has a basaltic $\left(\mathrm{SiO}_{2}: 50.71-52.06 \%\right.$; $\mathrm{MgO}: 8.13-$ $9.50 \%)$ and basaltic andesite composition due to magma mixing ( $\mathrm{SiO}_{2}: 52.90-53.42 \%$; $\left.\mathrm{MgO}: 6.71-7.12 \%\right)$ and is older in age ( $57 \mathrm{ka} \pm 13 \mathrm{ka}$ years B.P.). The Eastern composite lava field $\left(28.14 \mathrm{~km}^{2}, 1.14 \pm 0.25 \mathrm{~km}^{3}\right)$ has a basaltic andesite composition $\left(\mathrm{SiO}_{2}: 55.54-56.58 \%\right.$; $\mathrm{MgO}: 4.4-5.26 \%$ ) and is younger ( 16840 years B.P.). The Cervantes flows present a distinctive morphology of channels and levées, and hummocks hills. Their internal structure is composed of several massive lava units inter-layered by auto-breccias (including rare lava balls). The Western composite rubbly lava flow is thinner $(<20 \mathrm{~m}$ thick) and presents a clinker surface of overlapping flows. On the other hand, the Eastern is a composite (several flow units) rubbly and blocky lava flow, and it is thicker $(>20 \mathrm{~m}$ ), particularly when the lava became confined, achieving a thickness of $150 \mathrm{~m}$, and resulting into a complex joint prismatic structure that gave rise to the Cachí paleolake. Although the Western lava flow-field is more basic en composition (possibly more fluid), its smaller dimensions could be the result of a lower lava effusion rate, a higher cooling rate, and/or that the lava supply ceased. Instead, the Eastern basaltic andesite lava flow-field, originated from vents at lower altitudes, is thicker, longer and widespread lava field, with the larger sizes of levees, are presumable related to long-term effusion and/or higher average flow rate. The Eastern lava field presents areas without lava deposition (kipukas) and several depressions of different forms, which appear to be related to a crude snake pattern, and therefore could be the result of the lava flow filling fluvial valleys. The south flank of Irazú has a conjugated $\left(\mathrm{N} 34^{\circ} \mathrm{E}\right.$ and $\mathrm{N} 26^{\circ} \mathrm{W}, \sigma 1$ being oriented N04 $\left.{ }^{\circ} \mathrm{E}\right) 2 \mathrm{~km}$-long fissure system of craters and cinder cones, which was the source of the Cervantes lava fields. These volcanic trends are potential future sites for vertical feeder dikes and new effusive events.

Keywords: Geomorphology, blocky and rubbly lava flow, Cervantes lava flow field, Irazú, Costa Rica
\end{abstract}




\begin{abstract}
RESUMEN: La colada de Cervantes se ubica en el flanco sureste del volcán Irazú, en Costa Rica, y es el flujo de lava más reciente y grande datado en este volcán. Este campo está constituido por dos flujos de lava que presentan una composición diferente. El flujo occidental $\left(10,85 \mathrm{~km}^{2}, 0.18 \pm 0.1 \mathrm{~km}^{3}\right)$ es de composición basáltica $\left(\mathrm{SiO}_{2}: 50,71-52,06 \%, \mathrm{MgO}\right.$ : 8,13-9,50\%) y basáltica andesítica debido a mezcla de magma $\left(\mathrm{SiO}_{2}: 52,90-53,42 \%, \mathrm{MgO}: 6,71-7,12 \%\right)$, y es más viejo (57 ka $\pm 13 \mathrm{ka}$ años a.P.). El flujo oriental $\left(28,14 \mathrm{~km} 2,1,14 \pm 0,25 \mathrm{~km}^{3}\right)$ es de composición basáltica andesita $\left(\mathrm{SiO}_{2}: 55,54-\right.$ $56.58 \%$, MgO: 4,4-5,26\%) y es más joven ( 16 840 años a.P.). La colada de Cervantes muestra distintas morfologías superficiales tales como canales, levées y topografía tipo hummocky. La estructura interna de la colada está compuesta por varias unidades de lava masiva e intercalaciones de auto brechas (con presencia de bolas de lava). El flujo Occidental está compuesto por flujos de lava de tipo escoriácea y flujos en bloques, los cuales a su vez están cubiertos de ceniza, y con un espesor inferior a 20 m, con excepción del río Reventazón, en donde posee un espesor de aproximadamente 150 m, creando a su vez el paleo-lago Cachí. Sin embargo, el flujo Occidental presenta una composición más básica (posiblemente mayor fluidez), pequeñas dimensiones, tanto en espesor como extensión, resultado de bajas tasas de efusión, pendientes altas, y/o el cese de efusión de lava. El flujo Oriental fue originado a partir de fisuras ubicadas en sitios de baja altitud, y su espesor y extensión, además de la presencia de levées, son características que permiten relacionarlo con periodos de mayor efusión o descarga. Únicamente el flujo Oriental tiene zonas de no depositación de lava (kipukas) y una serie de depresiones de diferentes dimensiones y un patrón sinuoso, resultado de un antiguo valle fluvial cubierto por la lava. En el flanco sur del Irazú presenta un par tectónico conjugado $\left(\mathrm{N} 34^{\circ} \mathrm{E}\right.$ and $\mathrm{N} 26^{\circ} \mathrm{W}, \sigma 1$ orientado $\left.\mathrm{N} 04^{\circ} \mathrm{E}\right)$ conformado por una serie de fisuras, cráteres y conos, con una longitud de $2 \mathrm{~km}$, estructuras que constituyen la fuente de emisión de la colada de Cervantes. Dichos sectores podrían eventualmente presentar en el futuro actividad eruptiva.
\end{abstract}

Palabras clave: Geomorfología, lava en bloques y lava escoriáceos, campo de colada de lavas de Cervantes, Irazú, Costa Rica.

\section{INTRODUCCIÓN}

La colada de Cervantes se ubica en el flanco sur del Irazú (Fig. 1) y ha sido estudiada con cierto detalle por varios autores (Dóndoli \& Torres, 1954; Olson \&Sáenz, 1966; Krushensky, 1972; Thomas, 1983), y mencionada por muchos otros más. Sin embargo, no existe un estudio sinóptico y actualizado que sea fácilmente accesible por los geólogos, geógrafos, biólogos y guías turísticos, entre otros profesionales, con la salvedad de breves reseñas presentadas por el primer autor en su diferentes ediciones del libro Volcanes de Costa Rica (p.ej. Alvarado, 2011). En particular, la descripción de su cartografía difiere en detalle (extensión, contorno, área, etc.) según los diferentes autores.

Por ello, el objetivo primordial del presente estudio es presentar una actualización de este evento efusivo, uno de los más recientes y grandes, tanto en extensión como en volumen, de la cordillera volcánica Central, incluyendo su detallada descripción geomorfológica, petroquímica, geo-cronológica y aspectos socio-ambientales. También, se discute sobre su origen petrográfico bimodal y su contexto tectónico. De igual modo, se realizará una comparación entre ambos campos de lava, el Oriental y el Occidental.

\section{ANTECEDENTES}

Quizás uno de los primeros viajeros que describen la colada de Cervantes, sin percatarse que transitaba por ella, fue el alemán W. Marr (1863) en mayo de 1853, quien relata "En dirección del volcán se alza un laberinto de piedras colosales de un color gris negruzco, testigos de sus anteriores erupciones, como su un titán enfurecido los hubiera lanzado en medio de aquel sitio idilico" (Alvarado, 2011).

Williams (1952) igualmente comenta que en el trayecto que comunica Cartago con Turrialba, cerca del poblado de Cervantes, se presenta un flujo reciente proveniente del flanco sur del Irazú (Fig. 1). Describe dicha roca como una lava porfirítica con piroxenos, textura hialopilítica, asociados a basaltos o basaltos andesíticos.

Dondoli \& Torres (1954) indican que la colada de Cervantes está constituida por lavas andesíticas, a veces compacta, asociada con paquetes 


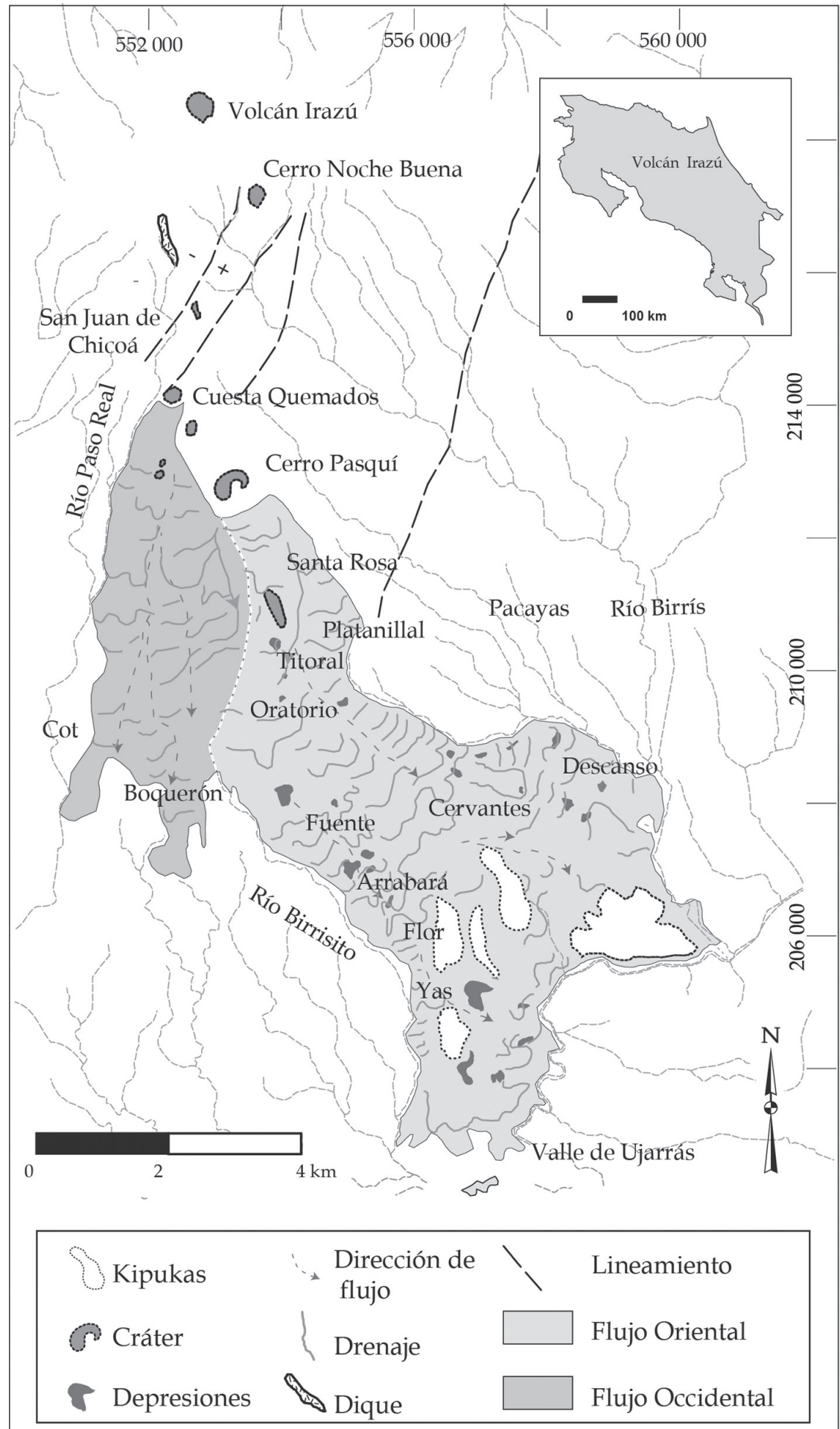

Fig. 1: Mapa de ubicación del volcán Irazú, sus cráteres y la colada de Cervantes. 
de escoria y material tobáceos. Además, indican que está poco meteorizada, por lo cual le asocian una edad más reciente, posiblemente la de la última erupción del Irazú. Agregan que cerca del río Birrís, camino a Turrialba, se observa un contacto quemado sobre aluviones.

En los estudios geológicos del Instituto Costarricense de Electricidad en el sitio de presa Cachí, se realizan una serie de perforaciones y descripciones, y se toman muestras para realizar dataciones de radiocarbono (Umaña, 1962; Murata et al., 1966; Umaña \&Alfonso, 1969).

Olson \& Sáenz (1966) la describen con detalle y determinan las unidades morfológicas por medio de la fotointerpretación y trabajo de campo. Concluyen que la colada de Cervantes se originó a 1,5 km al noroeste de cerro Pasquí y no en éste, pero que sí descansa sobre una colada del cerro Pasquí.

Kruschenky (1972) la cartografía y la denomina "Formación Cervantes"; mencionando la abundancia de túneles de lava colapsados y depresiones circulares.

Madrigal \& Rojas (1980) describen esta unidad geomorfológica enfatizando su gran irregularidad en superficie, dada por la presencia de bloques de lava semi-escoriácea cubiertos por cenizas recientes. Además, comentan que este flujo ocasionó acumulaciones de bloques que conformaron lomas longitudinales, y que la posible génesis de estas lomas cónicas es la acumulación de material o de hornitos. Le asignan una longitud de $11 \mathrm{~km}$ y un ancho de $5 \mathrm{~km}$ en la sección más ancha.

Thomas (1983) delimita y describe con detalle la morfología de la colada de Cervantes, y además propone las diferentes fuentes de extrusión, clasificando los flujos Oeste y Este según sus características petroquímicas. Desgraciadamente, este trabajo solo quedó como un trabajo de graduación y no fue publicado en una revista formal.

Tournon (1984) menciona que la colada posee una morfología caótica, delimitándola hacia el sur con el valle del río Cachí, y asignándole un área de $45 \mathrm{~km}^{2}$. Además, indica que está compuesta por una serie de coladas principalmente basálticas y andesitico-basálticas, las cuales fueron emitidas durante una fase efusiva a partir de conos estrombolianos tales como el cerro Pasquí y otros tres más ubicados a $1 \mathrm{~km}$ al norte de este (Fig. 1).

Alvarado et al. (2006) determinan la edad de las coladas mediante dataciones Ar-Ar, y la enmarcan dentro del contexto petroquímico. Agregan que la colada de Cervantes corresponde a un campo de lava de gran extensión a nivel centroamericano, y presenta dos fuentes de origen con un patrón de alineamiento norte-sur.

\section{METODOLOGÍA}

En la presente investigación se realiza una recopilación de material bibliográfico, además de diferentes mapas de la colada de Cervantes producidos por los diversos autores que se citan en este documento. Esta información nos permite delimitar la colada de Cervantes con una mayor precisión, apoyado por visitas de campo, el uso de fotografías áreas (de los años 1978, 1982, 1994; escala 1:10 000) y de imágines de radar, y de derivación de modelos elevación del terreno realizados en Sistemas de Información Geográfica. Para el cálculo del volumen, se tomaron algunos espesores medidos en el campo y con base en la topografía, y se realizó una estimación aproximada.

\section{GEOMORFOLOGÍA}

\section{Morfografía}

La zona delimitada por la colada de Cervantes presenta un incipiente desarrollo de hidrológico, donde se presentan muy pocas quebradas sin nombre, de escasa longitud y caudal, solo presente en épocas de lluvias debido a la elevada permeabilidad del terreno. Su principal característica morfológica es la gran cantidad de bloques, lo que le confiere el calificativo de malpaís, es decir, un lugar de difícil transitar. Esta unidad morfológica está delimita por cauces principales y desarrollados como los ríos Paso Real y Páez en la sección oeste, el río Birrís hacia el este y el Reventazón en su parte frontal. Sobre ella se desarrollaron poblaciones menores, pertenecientes al cantón 
de Alvarado (en honor al sacerdote José Joaquín Alvarado). La más importante es la de Cervantes que le da el nombre, y otras más pequeñas son Boquerón, Oratorio, Santa Rosa, etc. (Fig. 1).

\section{Morfogénesis}

La morfología de una colada de lava (características de la superficie, espesor, longitud, márgenes) está controlada la tasa de efusión, las propiedades físicas de la lava (densidad, reología, incluyendo su temperatura original y enfriamiento, desgasificación), la pendiente del terreno y topografía en general, la geometría del conducto eruptivo, y si su efusión ocurre en forma subaérea, subacuática o subglaciar, siendo la reología una de las más difíciles de cuantificar (Rittman, 1960; Macdonal, 1972; Walker, 1973; Kilburn \& Lopes, 1991; Pinkerton \& Norton, 1995; Kilburn, 2000; Castruccio et al., 2013).

Krushensky (1972) describe la morfología de Cervantes como una colada blocosa escoriácea, mientras que Salazar \& Madrigal (1994) comentan que es de tipo blocoso.

Aunque se suele hablar de la colada de Cervantes como un único ente, en realidad se trata de dos campos de lava independientes en edad y petroquímica: el Oeste u Occidental, de carácter basáltico hasta andesítico basáltico, y el Este u Oriental de composición andesítico basáltica y (Thomas, 1983; Tournon, 1984; Alvarado, 1993).

El campo Occidental está compuesto por flujos de lavas con espesores individuales de hasta 2 $\mathrm{m}$ en la sección masiva, autobrecha escoriáceas. En sus orígenes, cerca del foco de emisión, posiblemente fue del tipo aa, pero después, durante su avance, los fragmentos se quebraron y se redondearon por abrasión, siendo por ello una colada del tipo escoriácea o de escombros escoriáceos (rubbly), también llamada afrolítica (Alvarado, 1990; Kilburn, 2000). Su cobertura de cenizas alcanza espesores máximos de hasta $3 \mathrm{~m}$ en la sección proximal del flujo.

En el flujo Oriental se observa una mayor exposición de bloques, y el espesor de las cenizas es inferior a los 0,5 m. Dicho colada es del tipo tanto de escombros escoriáceos como en bloques.
Por otro lado, una serie de depresiones circulares a subcirculares, de diferentes formas y tamaño, se observan en los mapas topográficos, fotografías aéreas, imágenes digitales y en el campo (Figs. 1 y 2), cuya génesis no es clara. Algunos de ellos podrían representar cráteres asociados con la actividad fisural, cráteres de explosión freática, estructuras de colapso de túneles de lava (jameos) $\mathrm{u}$ otro origen poco estudiado. Olson \& Sáenz (1966) discuten, por ejemplo, si las depresiónde Titoral corresponde con un cráter, concluyendo que posiblemente no lo sea. Thomas (1983) opina que las depresiones en Fuente y Arrabará puedan ser focos eruptivos, aunque el mismo comenta que no son muy simétricos o circulares.

Krushensky (1972) comenta la existencia de depresiones circulares y alargadas. Describe las depresiones alargadas con dimensiones de menos de $1 \mathrm{~km}$ de largo y unas decenas de metros de ancho, hasta excepcionalmente $2 \mathrm{~km}$ de largo por $200 \mathrm{~m}$ de ancho, o de $3,4 \mathrm{~km}$ de largo por 200 $\mathrm{m}$ de ancho (entre el camino de Fuentes al oeste de Arrabará hasta el camino del Pedregal, cerca de Yas). Krushensky (1972) los interpreta como túneles de lava colapsados. Madrigal (1977) denomina a estas geoformas como colinas de tubo de lava, que dan origen a la conocida topografía de canoas. Thomas (1983), en cambio, los interpreta más bien como levées (palabra francesa que significa terraplén, dique, malecón o albardón) similares a otros campos de lavas en el mundo, interpretación que se comparte en el presente trabajo (Fig. 3).

Aunque las depresiones alargadas corresponden con léeves, Thomas (1983) describe un flujo secundario originado desde una boca casual de un pequeño túnel de lava (un metro de ancho). Alvarado (2011) menciona grutas menores de lava. Un túnel de lava de mayor tamaño, del cual se tenía noticias verbales desde hace varios años, finalmente se localizó durante la presente investigación al NE de la localidad de Oratorio (554700209710). Se observa una depresión rectangular de unos $100 \mathrm{~m}^{2}$, que corresponde con una venta de acceso por el colapso del techo de un túnel de lava (denominados "jameos" en Las Islas Canarias), en donde todavía se preserva parte de la entrada de los dos túneles. La entrada posee una altura de 


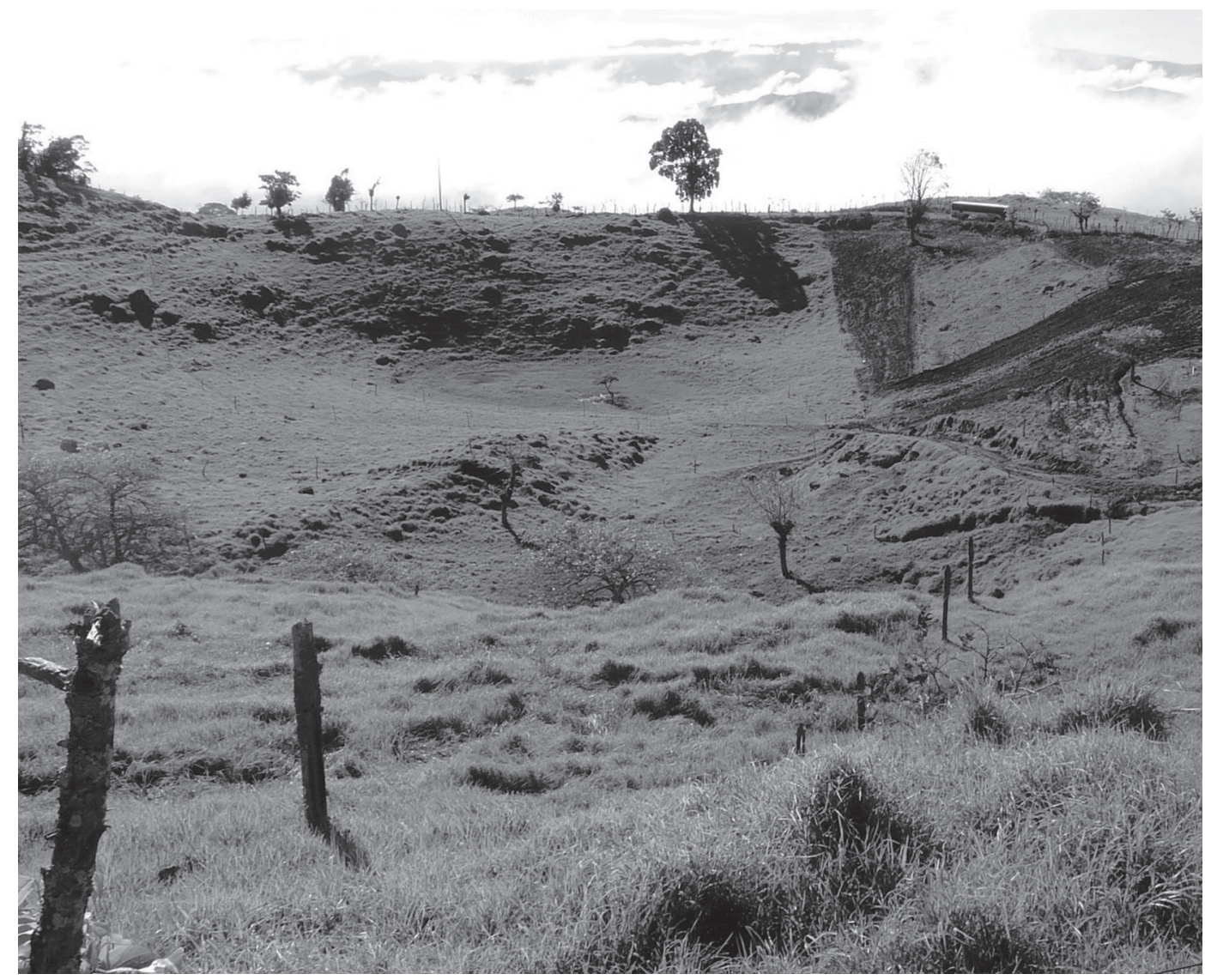

Fig. 2: Depresión de Titoral.

aproximada de $1,5 \mathrm{~m}$ y una profundidad de algunos metros, estando en parte rellena por el colapso de bloques y por basura depositada por los locales (Fig. 4). Debido a ello, posiblemente, se acumuló en el pasado gas metano, y dos lugareños murieron al internarse en uno de ellos con una vela para alumbrarse, y ocurrir una explosión.

\section{Morfometría}

Para delimitar los dos flujos de la Colada de Cervantes, se ha estudiado la dirección de los flujos y su petrografía.

La longitud máxima de los campos Occidental y Oriental desde su fuente de origen es de 7 y 10 $\mathrm{km}$, respectivamente. Las pendientes en ambos campos varían entre $4^{\circ}$ y $20^{\circ}$, con excepción de los flancos de los levées más pronunciados. Más en detalle, la morfología superficial del flujo Occidental es de pendiente relativamente más suave debido a una mayor cobertura de cenizas, con espesores superiores a $\operatorname{los} 3 \mathrm{~m}$, las cuales posiblemente fueron emitidas del cerro Pasquí. Por otro lado, en el campo Oriental, el grosor de las cenizas es significativamente menor, y más aún conforme se aproxima a Cachí.

El espesor de la colada varía entre unos pocos metros y 25 m (p.ej. cerca de San Martín) hasta unos 200 m (Salazar \& Madrigal, 1994) o incluso 220 m (Krushensky, 1972), donde rellenó el cauce del río Reventazón, aunque las perforaciones en el sitio de la represa de Cachí reportan espesores entre 30 y 80 m (Umaña, 1962; Umaña \& Alfonso, 1969). Efectivamente, en la localidad de Piedra Azul, colindante con el cañón del Reventazón, se 


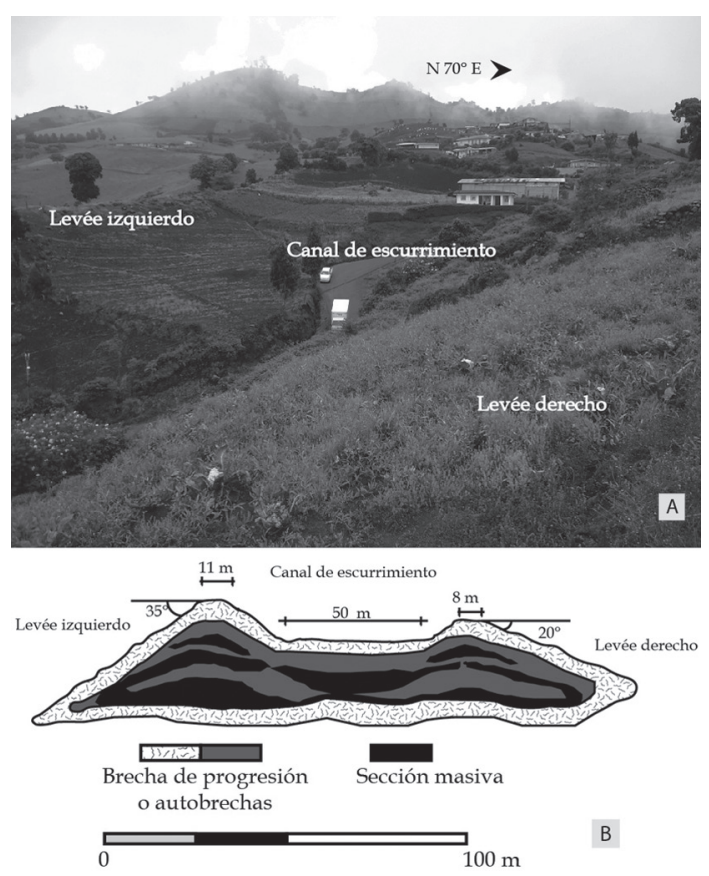

Fig. 3: Morfología típica de Cervantes con su levée y su canal central de escurrimiento. A: canal central, utilizado hoy día como carretera que comunica Santa Rosa con Platanillal. B: Sección esquemática del levée de Platanillal mostrado en A.

puede estimar un espesor mínimo de $150 \mathrm{~m}$, pero no se conoce el espesor máximo. Se desconoce cómo otros autores llegaron a estimar los espesores de 200 m o más.

Olson \& Sáenz (1966) estiman un área total para la colada de Cervantes de $35 \mathrm{~km}^{2}$, con un volumen estimado de $0,35 \mathrm{~km}^{3}$. Thomas (1983) establece una longitud total del flujo Occidental de $7 \mathrm{~km}$ un área de $10,5 \mathrm{~km}^{2}$, y un volumen estimado de $0,173 \mathrm{~km}^{3}$; mientras que el flujo Oriental cubre $31,5 \mathrm{~km}^{2}$ y tiene un volumen estimado de $0,882 \mathrm{~km}^{3}$ (Thomas, 1983). Nuestros cálculos nos permiten concluir que las coladas Occidental y la Oriental poseen una cobertura de $10,85 \mathrm{~km}^{2} \mathrm{y}$ $28.14 \mathrm{~km}^{2}$, respectivamente. Mientras que el área se puede calcular con bastante precisión, no así el volumen, aunque se puede efectuar un estimado grosero tomando en cuenta algunos espesores medidos en el campo y con base en los mapas topográficos. Así, su volumen estimado sería de 0,18 \pm 0.1 y $1.14 \pm 0.25 \mathrm{~km}^{3}$ para el campo Occidental y Oriental, respectivamente.
En general, en ambos campos, los frentes de las coladas son abruptos (entre 7 y 25 de altura), pero se suelen perder entre un mar de unidades de flujo entrelazadas. Además, se observan cerros de acúmulos de lava y promontorios, posiblemente debido a un incremento en el espesor por el proceso de inflación.

Varias localidades, sin embargo, no fueron cubiertas por las lavas, quedando como "islas de vida" o kipukas, entre varias de ellas, Yas y Flor (Fig. 1). Allí se logran observar suelos antiguos con un fuerte desarrollo en la meteorización y colores rojizos.

\section{Litología}

Varios autores aportan cierto detalle petrográfico y geoquímico, entre ellos Krushensky (1972), Thomas (1983), Tournon (1984), Alvarado (1993) y Alvarado et al. (2006).

El flujo Occidental posee una composición basáltica con muestras básicas $\left(\mathrm{SiO}_{2}\right.$ : 50,7152,06\%; MgO: 8,13-9,50\%; Cr: 380-395 ppm; Ni: 160-199 ppm) a otras andesítico basálticas con indicios de hibridización o mezcla $\left(\mathrm{SiO}_{2}\right.$ : 52,90-53,42\%; MgO: 6,71-7,12\%; Cr: 216-232 ppm; Ni: 115-203 ppm). Las lavas vesiculares están conformadas por un $24-40 \%$ de fenocristales, entre ellos plagioclasa $\left(12 \%, \mathrm{An}_{62-82}\right)$, olivino (7$\left.8 \% ; \mathrm{Fo}_{90-72}\right)$, sanos e idiomórficos o parcialmente iddingsitizados con inclusiones de espinela cromífera; además de fenocristales de clinopiroxenos $\left(4 \%, \mathrm{En}_{44-45} \mathrm{Fs}_{16} \mathrm{Wo}_{39-40}\right)$, bajo contenido de ortopiroxenos $(0,5 \%)$, a veces con corona de clinopiroxeno; minerales opacos $(8 \%)$, y el restante corresponde con la matriz pilotaxítica, compuesta por plagioclasa, piroxenos, olivino $\left(\mathrm{Fo}_{65}\right)$, titanomagnetita, magnetita cromífera e ilmenita.

Las lavas del flujo Oriental son clasificadas como andesitas basálticas algo más ácidas $\left(\mathrm{SiO}_{2}\right.$ : 55,54-56,58\%; $\mathrm{MgO}: 4,4-5,26 \%$ Cr: 119-130 ppm; Ni: 50-64 ppm). Poseen un moderado a alto contenido de fenocristales (aprox. 30-45\%) de plagioclasa $\left(23-30 \%, \mathrm{An}_{40-68}\right)$ de 3-4 m de largo, y mayor contenido de piroxenos, entre ellos, clinopiroxenos $\left(6-9 \%, \mathrm{En}_{45} \mathrm{Fs}_{15} \mathrm{Wo}_{41}\right)$ y ortopiroxenos $\left(1-4 \%, \mathrm{En}_{69}\right)$, algunos de estos últimos rodeados 


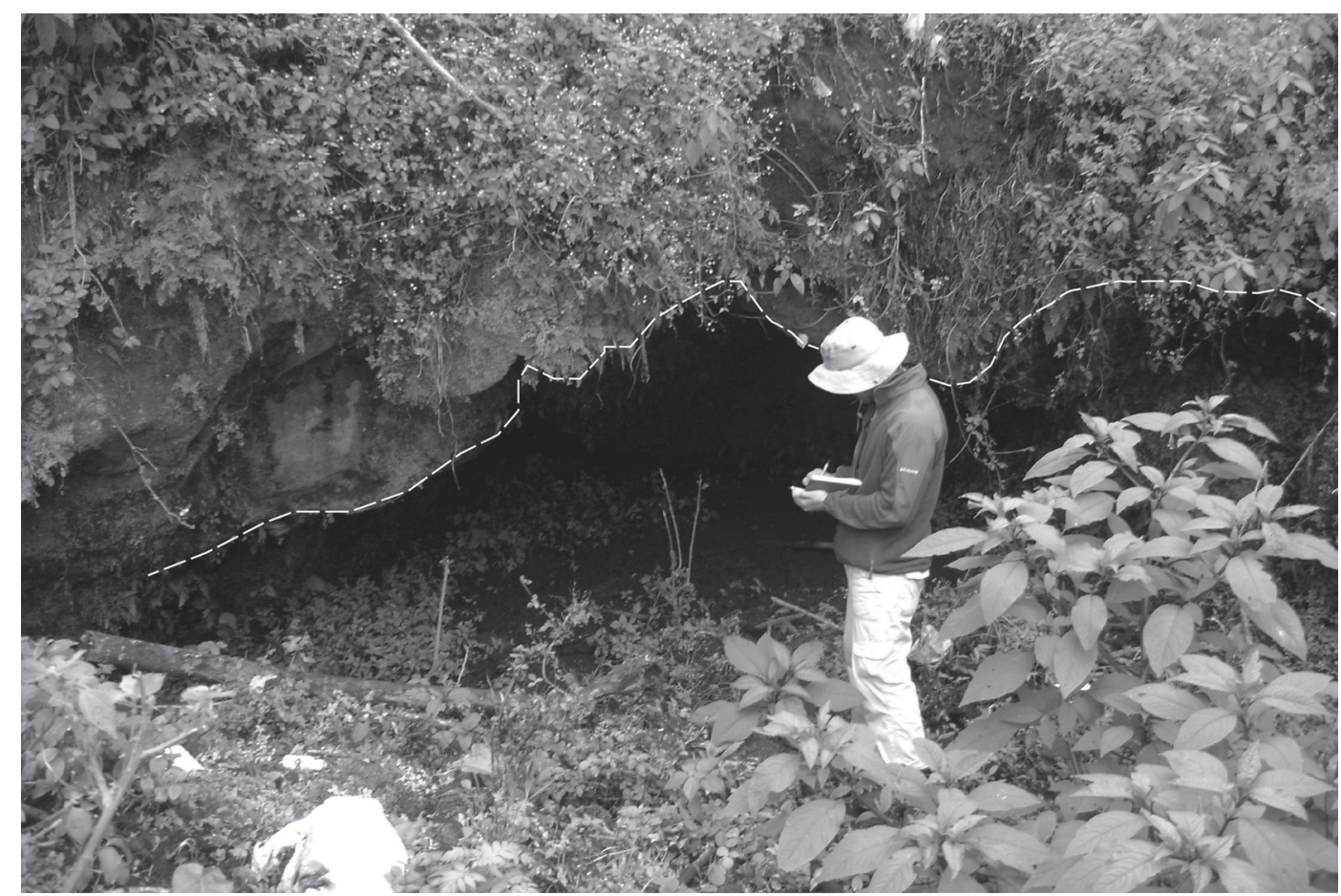

Fig. 4: Entrada al túnel de lava en Oratorio.

por clinopiroxenos y raramente anfíbol, y algo ( $\leq$ $4 \%)$ a muy poco olivino $\left(\mathrm{Fo}_{89}\right)$ con inclusiones de espinela; también se presentan microfenocristales de titanomagnetita. La matriz es hialopilítica hasta intersertal, constituida por microlitos de plagioclasa $\left(\mathrm{An}_{42}\right)$, clinopiroxenos $\left(4 \%, \mathrm{En}_{44-45} \mathrm{Fs}_{16} \mathrm{Wo}_{39-40}\right)$, ortopiroxenos, vidrio (algunos riolíticos), titanomagnetita e ilmenita.

Sería interesante en un futuro analizar los olivinos ricos en fosterita para dilucidar si cristalizaron a partir de un líquido (liquidus) o si son xenocristales de peridotitas (Tournon, 1984; Tournon, com. verbal, 2013).

\section{Estructura interna}

En un tajo ubicado inmediatamente al norte de la comunidad de Santa Rosa (Fig. 9), se observa la colada Occidental, compuesta por al menos 5 unidades de flujo, es decir, coladas masivas separadas por autobrechas de progresión. También se observan bloques métricos de lava subredondeados, escoreáceos, semejantes a las denominadas "bolas de lava" (lava balls o accretionary lava balls sensu Macdonal, 1972), producto del rodamiento y fricción de bloques pastosos de lava, por lo que ocasionalmente pueden mostrar una estructura espiral y en capas (Fig. 5a). Al este de Titoral, en el tajo Platanilla (Fig. 9) la colada está compuesta por al menos 10 unidades de flujo, donde se observa la coexistencia estratigráfica de lavas en bloques con lavas de escombros escoriáceos (Fig. 5b). Los bloques son decimétricos en su mayoría, aunque también abundan los bloques poliédricos métricos. La parte coherente o masiva de las coladas varía entre 2 y 4 m, estando separadas por autobrechas. Las lavas masivas suelen no poseer estructuras mayores, aunque se observaron localmente fracturas en échellon que sugieren esfuerzos de tracción durante el transporte del flujo en vías de enfriamiento (Fig. 5c). Las vesículas pueden estar horizontalmente concentradas o con cierta estructura imbricada en el sentido del flujo (Fig. 5d). 

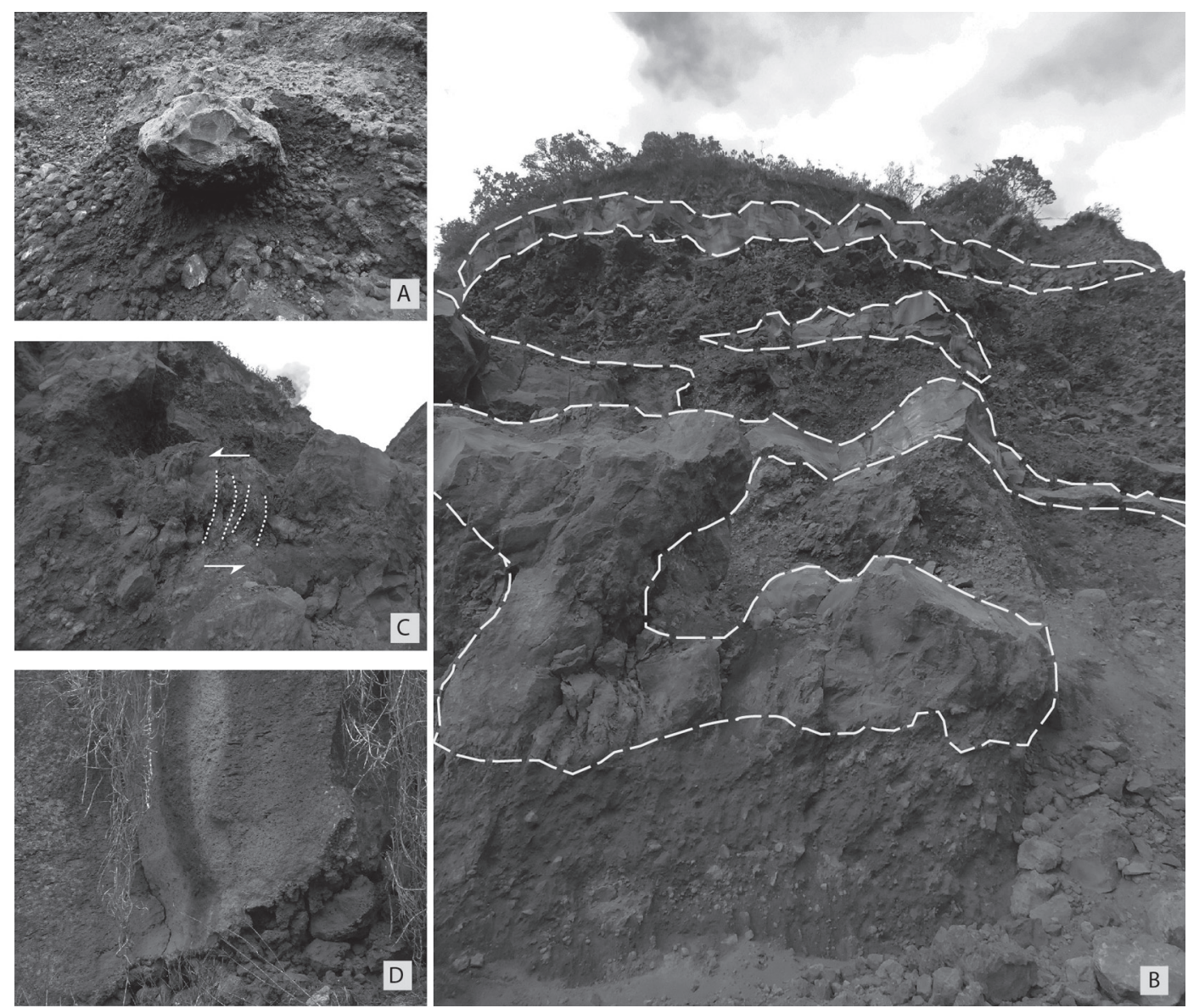

Fig. 5: a) Bola de lava, b. Unidades de flujo separadas por brechas de progresión o autobrechas, c) Posibles fracturas en échellon, d) Detalle de la parte masiva de una colada con sus vesículas.

La colada Occiental parece ser menos espesa, no solo en las unidades individuales masivas entre 1 y $2 \mathrm{~m}$ de espesor, sino en el espesor acumulado (quizás unos $20 \mathrm{~m}$ máximo), estando compuesta por un mínimo de cuatro unidades de flujo. Algunas presentan una superficie preservada relativamente masiva aunque, en la mayor parte de los casos, las autobrechas superficiales son de tamaños decimétricos y altamente escoriáceas. Se han llegado de observar montículos, que parecen ser el resultado de acúmulos de lava debido al proceso de inflación, cuyos autoclastos tuvieron un transporte efímero, posiblemente por rodamiento local.
Aunque no se han realizado análisis cuantitativos, los levées parecen ser más grandes (anchos y altos) en el campo Oriental, muy posiblemente relacionado con una mayor viscosidad de las lavas, aunque en general los levées sobre pendientes mayores suelen ser menos altos y anchos que sobre pendientes suaves (Walker, 1973). El canal central de los leéves puede tener entre 10 y $40 \mathrm{~m}$ de diferencia de elevación entre su base y la parte superior (Fig. 3).

En el sitio de la represa de Cachí, posee tres zonas diferentes en cuanto a su condición física: la superior muy diaclasada y vesicular, la intermedia masiva con estructuras columnares verticales y la 
inferior, nuevamente muy fracturada y vesicular. El contacto inferior con el lacustre está completamente impregnado con materiales plásticos que subieron por las fisuras e intersticios de la lava, presionadas por el peso litostático de la colada suprayacente (Umaña \& Alfonso, 1969), que podrían corresponder con peperitas (ver Soto \& Alvarado, 2012). Desde el cementerio cerca de Urasca, margen derecha del Reventazón, se observa que la colada de Cervantes posee un desarrollo de al menos dos niveles con disyunción columnar vertical, columnas en semi-rosa y diaclasas horizontales, indicativas de un proceso lento de enfriamiento, quizás debido a que la colada se acumuló en esta depresión, incrementando notablemente su espesor (Fig. 6).

\section{Fuente de origen}

La toma de muestras de roca para geoquímica indica dos focos de origen diferentes (Thomas, 1983; Tournon, 1984; Alvarado, 1993), lo mismo que su geocronología (Alvarado et al., 2006). La colada Occidental se originó en una fuente múltiple, compuesta por tres focos localizados cerca de la cuesta los Quemados con alturas aproximadas de 2700 (cono volcánico sin nombre), 2580 y 2580 m.s.n.m. (ambos cráteres simétricos sin nombre, Fig. 7 a y b) y dos posibles conos más al sur de San Juan de Chicoá con alturas de 2740 y 2800 m.s.n.m., a lo largo de una fisura de unos $2 \mathrm{~km}$ de longitud con rumbo N34드. El campo de lavas Oriental, en cambio, se originó a partir de una fisura de unos $2 \mathrm{~km}$ de longitud con rumbo $\mathrm{N} 26^{\circ} \mathrm{W}$, desde el cono de escorias Pasquí (2554 m.s.n.m.), hasta el cráter elongado ( 2080-2060 m.s.n.m.) que culmina al norte con el cráter circular de Santa Rosa ( 2060 m.s.n.m.) (Ver figuras 7 b, c y d). El Pasquí posee forma de herradura abierta hacia el sur, por lo que morfológicamente se le clasifica como un cono desportillado (aportillado). La parte que falta del cono y cráter, posiblemente fue arrastrada por la colada, no permitiendo que se depositaran piroclastos durante la erupción.

\section{Morfocronología}

Dóndoli \& Torres (1954) especulan un origen geológicamente muy reciente, mientras que Olson \& Sáenz (1966) asumen que la colada Occidental es más joven que la Oriental. En trabajos efectuados por el ICE durante la construcción de la presa de Cachí, alrededor de 1963, se hallaron muestras de madera en una paleo-terraza fluvial bajo la colada de Cervantes. El resultado de las dataciones de ${ }^{14} \mathrm{C}$, corresponden con edades de $13800 \pm 300$ años a. P. (Murata et al., 1966) y $14260 \pm 160$ a.P. (Alvarado, 1993). Dichas edades calibradas suministran rangos de 15670 - 17480 años y 16 500-17 710 años a.P., respectivamente, para un edad promedio calibrada de 16840 años a.P. (Alvarado et al., 2004). Una datación ${ }^{238} \mathrm{U} /{ }^{230} \mathrm{Th}$, presumiblemente de la colada Oriental, resulta en 23000 años (Allègre \& Condomines, 1976). Por su parte, las dataciones realizadas con ${ }^{40} \mathrm{Ar} /{ }^{39} \mathrm{Ar}$ indican una edad de $20000 \pm 12000$ años para la colada Oriental, acordes con las dataciones previas, y de $57000 \pm 13000$ años para la colada basáltica Occidental (Alvarado et al., 2006). Se concluye entonces que la colada Oriental fue emitida hace unos 16900 años (tomando en cuenta que a.P. se mide a partir de 1950) y que la Occidental hace unos 57000 años. Efectivamente, los espesores de ceniza son mayores en la colada Occidental, hecho favorecido por ser más vieja y por estar en la dirección predominante de la caída de ceniza procedentes del Irazú -y sus conos parásitos- y del Turrialba.

\section{USOS ECONÓMICOS}

Olson \& Sáenz (1966) reconocen mediante fotografías áreas que las dimensiones de las parcelas de cultivo (en aquel entonces predominantemente de café) son de dos a tres veces más grandes fuera de la colada que sobre esta, debido a lo agreste del terreno. Además, comentan que las zonas de pastos predominan fuera de la colada. Aún hoy día, los cultivos, aunque abundantes 


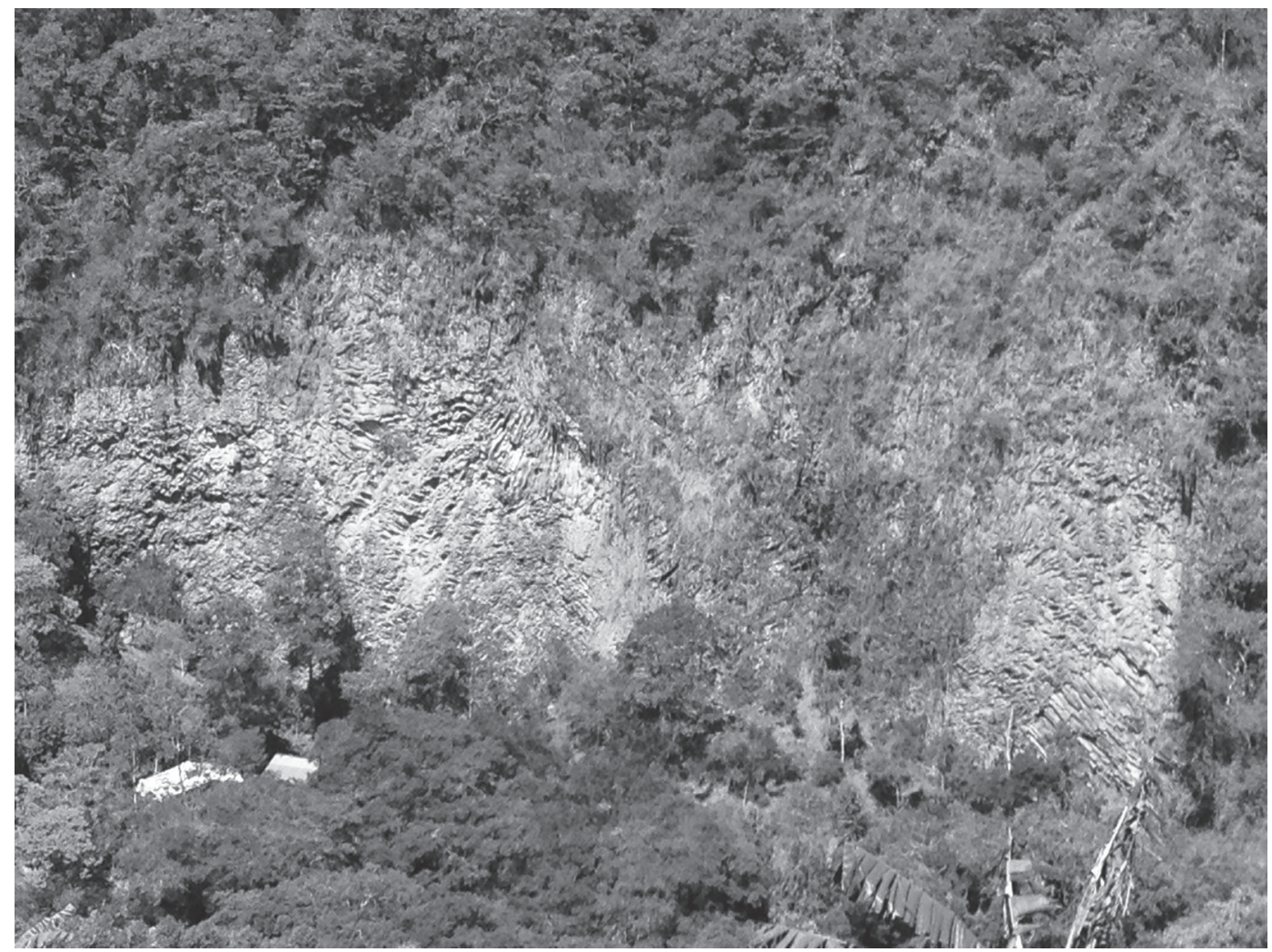

Fig. 6: Detalle de la estructura prismática en los acantilados del río Reventazón.

(papas, hortalizas), poseen el inconveniente de la gran cantidad de bloques. También se tiene presente el ganado de leche.

Alvarado et al. (2002) comentan que la denominada Lava Negra (Piedra Sánchez) porosa y negra, usada como recubrimiento o enchape de tapias, aunque originalmente provenía de Heredia, en la actualidad se extrae de La colada de Cervantes. Hoy día, muchos de los bloques de lava recortados son usados para tapias y cercas de piedra ornamental en los alrededores de Cervantes (Fig. 8).

Thomas (1983) y Kussmaul et al. (1993), señalan en sus mapas los lugares donde se extraen materiales para construcción (canteras, localmente conocidas como tajos). La Fig. 9 señala dichos lugares (activos y abandonados), complementados con la presente comprobación de campo y la consulta de los archivos de la Dirección de Geología, Minas y Petróleo.

\section{DISCUSIÓN}

El presente estudio cartografía la colada de Cervantes, que se extiende por un área de unos 39 $\mathrm{km}^{2}$, y posee un volumen total estimado de 1,32 \pm $0,26 \mathrm{~km}^{3}$. Su espesor varía entre 7 y $25 \mathrm{~m}$, excepto en los sitios donde rellenó valles, que alcanza una potencia superior a los $150 \mathrm{~m}$.

Se ha establecido que el avance de una colada de lava se suele detener debido a tres factores principales: a) una marcada reducción en el suministro de lava en la fuente y canal, b) cambios topográficos fuertes durante su avance, y c) cambios 


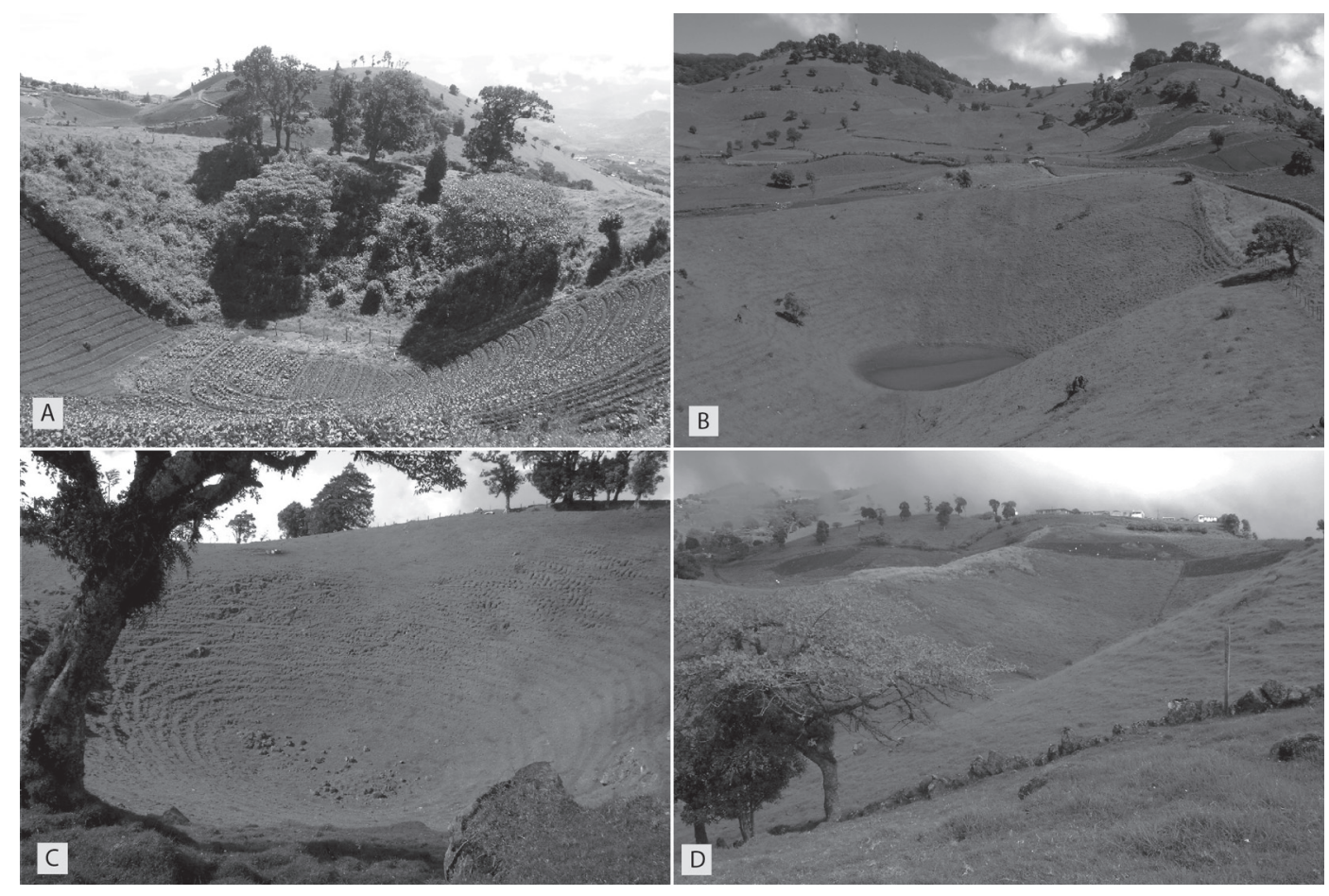

Fig. 7: Detalle de los focos eruptivos físurales: a) Uno de los cráteres de Quemados con el cono Pasquí al este, b) otro de los cráteres de Quemados con cultivos con el Pasquí al norte, c) Cráter de Santa Rosa, d) fisura de Santa Rosa.

en las propiedades de la lava como consecuencia de su enfriamiento (Guest et al., 1987; Pinkerton \& Wilson, 1994). Con base en ello, analizaremos a continuación el caso de ambos campos de lava.

La colada Occidental, pese a ser basáltica -teóricamente más fluida-, posee un contenido relativamente elevado de fenocristales ( $24-40 \%$ ), que sugiere una viscosidad moderada. Dicha colada detuvo su avance después de haber recorrido tan solo $7 \mathrm{~km}$, en comparación con la Oriental que, pese a ser andesítica basáltica y ligeramente más rica en fenocristales (30-45\%), recorrió $10 \mathrm{~km}$, formando un extenso abanico de lavas. Al no existir cambios o barreras topográficas significativas durante el recorrido del flujo Occidental, el hecho de que se detuviera debió de estar relacionado con un corte en el suministro de lava. Otro posible factor es que su avance haya estado afectado por un enfriamiento significativo (quizás relacionado con su menor espesor y el tipo de lava), factor que parece ser menos importante en las coladas blocosas (ver Takagi \& Huppert, 2010; Castruccio et al., 2013).
Adicional y particularmente, en volcanes maduros la tasa de efusión generalmente decrece con el incremento de la altura del foco eruptivo (Kilburn, 2000), caso que pudo presentarse en el Irazú. La fisura que debió de dar origen al campo Occidental se localizaba en un rango de altura de 2700-2500 m.s.n.m. (altura original, sin el ulterior crecimiento de los conos de escorias), es decir, más elevado que el Oriental.

En contraposición, el flujo Oriental presenta una historia más compleja de ramificación con mayores espesores, longitudes y anchos del campo andesitico basáltico. En su caso, los varios focos de alimentación estuvieron localizados a alturas inferiores dentro del rango de 2400-2000 m.s.n.m. (alturas originales), y por consiguiente, la tasa efusiva fue probablemente mayor. Todo lo anterior sugiere un suministro más continuo de lava, tal y como demuestra su mayor espesor, el estar compuesto por al menos 10 unidades de flujo, y por su amplia dispersión areal. El cono Pasquí, uno de los focos de origen de este flujo, 


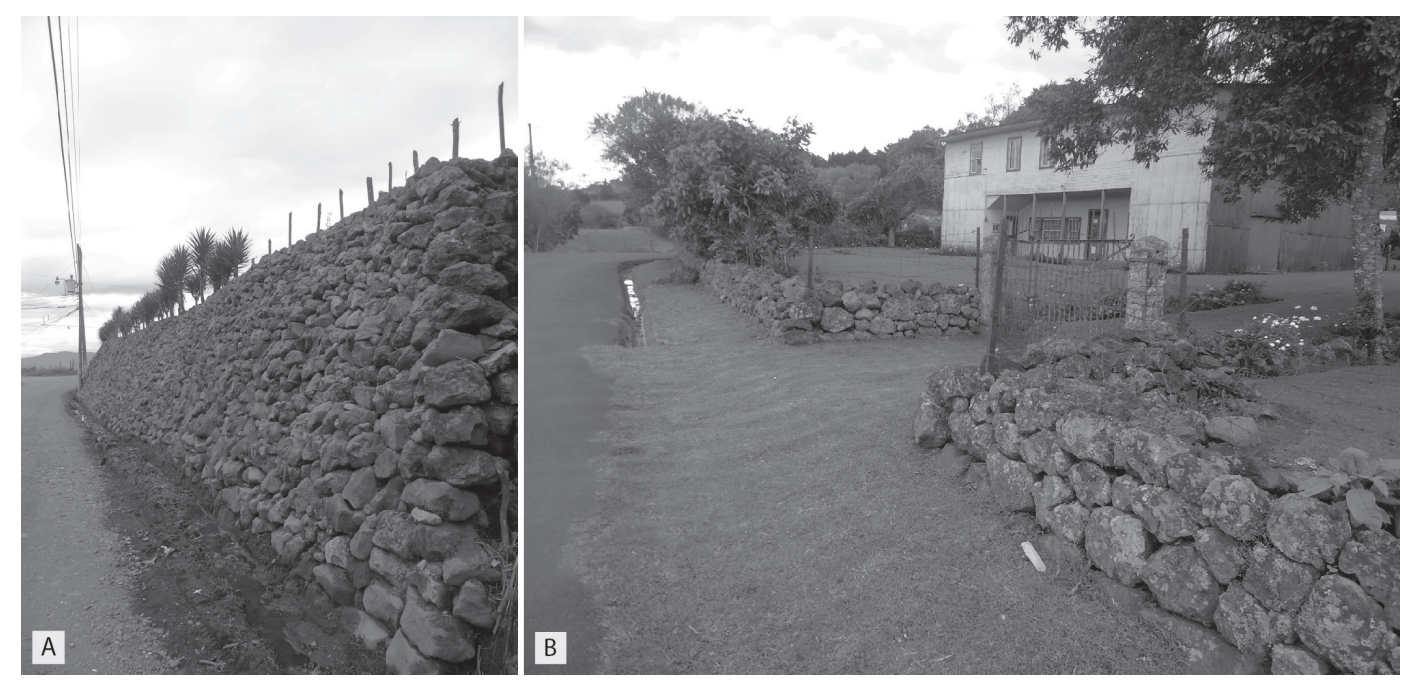

Fig. 8 Dos ejemplos del uso de las piedras de Cervantes para tapias ornamentales.

está bien desarrollado y alcanza una altura relevante sobre el relieve circundante, indicando una actividad importante. La colada finalmente detuvo su recorrido al llegar al río Reventazón, rellenando su profundo paleo-cañón (al menos de $100 \mathrm{~m}$ o más de profundidad), y al chocar contra el cerro Congo y sus estribaciones, aunado a su enfriamiento al contacto con las aguas del río, que debió de favorecer adicionalmente su detención.

\section{Forma y origen de los levées}

Los levées son abundantes en la colada de Cervantes. Se presentan con mayores dimensiones en el campo Oriental, tanto en ancho como longitudinalmente. La sección media hacia la localidad de Cot, por ejemplo, presenta levées con dimensiones de hasta los $40 \mathrm{~m}$ de ancho, en diferencia con la Oriental, donde presentan un ancho superior a los $80 \mathrm{~m}$. La parte inferior del flujo cerca de Boquerón está conformada por pendientes que varían desde los $15^{\circ}$ a $10^{\circ}$. Hacia el sur de Boquerón se presenta la mayor extensión del flujo con $200 \mathrm{~m}$ de ancho y con $30 \mathrm{~m}$ hacia el frente.

La morfología del flujo Oriental cerca de la base del cerro Pasquí está conformada por 3 cerros alargados de forma paralela entre ellos, lo cual puede identificarse como levées, morfologías se extienden desde el cerro Pasquí hasta el embalse de Cachí.

\section{Origen de las depresiones y kipukas en la colada}

Una diferencia muy notoria es la abundancia de depresiones y de kipukas en el campo de lavas Oriental con respecto al Occidental, en donde están ausentes.

Algunas depresiones circulares corresponden sin duda a cráteres eruptivos (Pasquí, Quemados y Santa Roca), y tan solo una depresión pequeña corresponde con el colapso del techo de un túnel de lava pequeño, tal y como de mencionó previamente. Algunos autores consideran que otras puedan también ser cráteres, como la del Titoral, Fuente y Arrabará (Thomas, 1983); la interpretación en el presente trabajo, sin embargo, es diferente. Se trata de depresiones importantes, de unos 30-40 m de profundidad, con una forma bastante irregular tanto en su perímetro como en sus paredes y fondo (Fig. 3). Al observar su distribución, se desprende que se alinean de forma serpentiforme y que su tamaño incrementa con la distancia desde el foco eruptivo que dio origen a la colada (Figs. 1 y 10). Por tanto, se puede pensar 


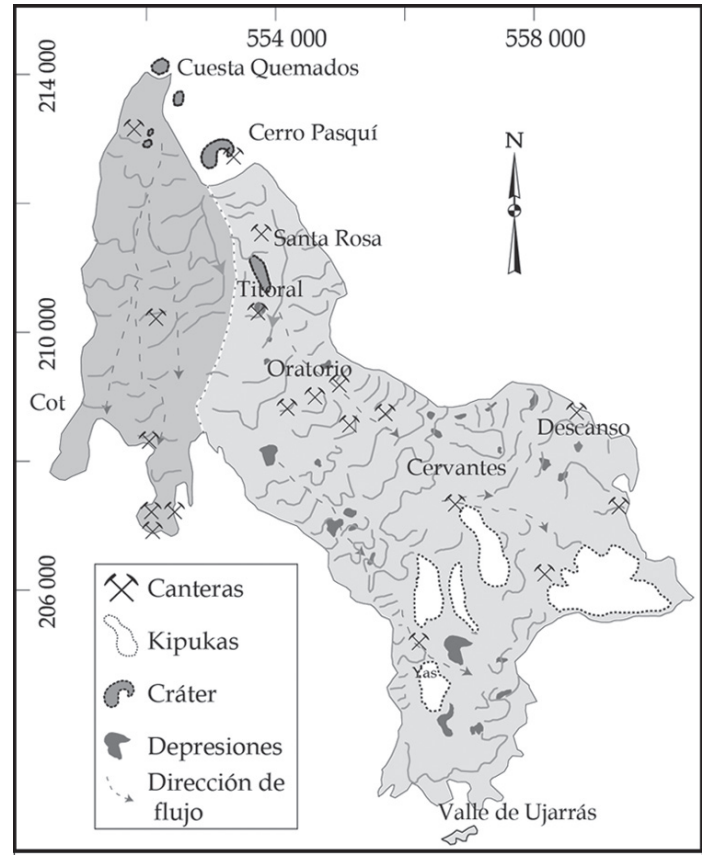

Fig. 9: Ubicación de los tajos activos e inactivos en la colada de Cervantes.

que las depresiones pudieron generarse cuando la colada de lava fluía sobre cauces de ríos, hoy día cubiertos o desplazados, y que su incremento en tamaño puede ser causa del ensanchamiento del valle, reflejando el paleo-relieve de antiguos valles fluviales. Quizás por ello, unas pocas -pero no todas- podrían corresponder incluso con cráteres de explosión freática, pero no se hallaron evidencias que lo soporten. Ya Olson \&Saenz (1966) hablaban de que es posible que el río Birrís haya sido obligado a desplazarse hacia el oriente de su anterior valle. En efecto, se determina que la quebrada Pacayas, afluente del Birrís, claramente fue desplazada de su curso hacia el oriente, mientras que el río Birrís lo hizo únicamente en su último tramo, después de la confluencia con la Pacayas.

Las kipukas también son más abundantes y grandes con la distancia de la fisura eruptiva (Figs. 1 y 10). Esto puede ser un indicador de un relieve más accidentado, tales como las gradas geomorfológicas regionales presentes en la falda austral del Irazú a alturas de 1500, 1200 y 1000 m.s.n.m., en las cuales justamente si se proyectan hacia la presente disposición de la colada, se observa que allí se presentas las mayores ventanas sin depositación de la colada de Cervantes.

\section{Comparación entre los campos Oriental y Oc- cidental de Cervantes con los campos de lavas de Arenal}

Las diferentes composiciones petroquímicas de los dos campos de lava, el Occidental más máfico y el Oriental más intermedio, influenciaron las diferentes morfologías y el ancho de los levées. El flujo Oriental posee levées de mayores dimensiones, tanto en longitud, ancho y altura; además de una mayor cantidad de ellos, por contrario a los que se observa en el campo Occidental, donde las dimensiones son menores.

Basándonos en Castruccio et al. (2013), resulta probable que la colada Occidental tuviese un régimen dinámico dominado por un esfuerzo cortante en el crecimiento de la corteza de la colada, mientras que la colada Oriental fue transicional entre el crecimiento de corteza y el esfuerzo cortante interno del núcleo de la colada.

La colada generó ciertos cambios morfológicos importantes a nivel de meso-relieve, pero no alteran significativamente el contorno de las curvas de nivel, tal y como se aprecia los mapas de pendientes y de relieve (no incluidos). Una diferencia muy notoria, ya explicada, es la abundancia de depresiones y de kipukas en el campo de lavas Oriental con respecto al Occidental donde están ausentes (Fig. 1).

Al graficar en el diagrama de Walker (1973), el espesor individual de las coladas de ambos campos de lava (2-4 m para la Occidental y unos 5-10 m Oriental, respectivamente) versus el área total $\left(10,85\right.$ y $\left.28,14 \mathrm{~km}^{2}\right)$ y el diámetro del círculo imaginario que las representa, se observa que (Fig. 11):

a) el campo Oriental se ubica dentro de las lavas de alta viscosidad, relación baja E/A (espesor/ ancho), y dentro de los rangos de volumen cercanos al kilómetro cúbico.

b) el campo Occidental, por su parte, se ubica dentro de las lavas de viscosidad baja, relación baja $\mathrm{E} / \mathrm{A}$ y un volumen inferior.

En efecto, las lavas aa suelen ser más abundantes en los flujos basálticos hasta andesítico basálticos, caso del Occidental, mientras que las coladas en bloques se presentan en los flujos más viscosos, normalmente con $\mathrm{SiO}_{2}>55 \%$, 


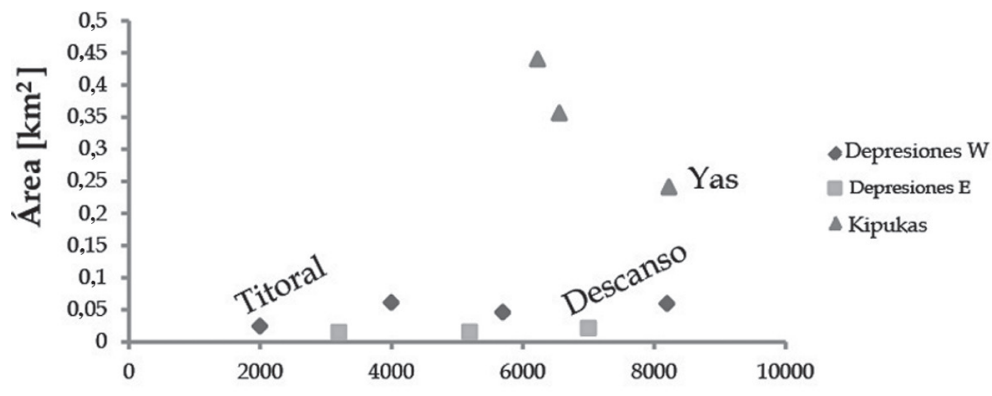

Distancia [m]

Fig. 10: Diagrama que muestra la variación en el área de las depresiones y de las kipukas versus la distancia con respecto al cono eruptivo superior de cada campo.

tal y como se observa en la campo de lavas Oriental (ver Rittmann, 1960; Macdonal, 1972; Kilburn, 2000).

Claramente, al ser la colada de Cervantes prehistórica, y corresponder con un campo de lavas complejo, conformado por varios flujos superpuestos e interdigitados (incremento en el espesor), las fórmulas empíricas para calcular el tiempo y tasa de efusión (ver por ejemplo, Kilburn \& Lopes, 1991) no se pueden aplicar de manera directa o simplificada. Para Walker (1973), Wadge (1978) y Pinkerton \& Wilson (1994), entre otros, los flujos más largos suelen estar asociados con tasas de efusión mayores. En el Etna, sin embargo, se ha observado que incluso con diferentes tasas de efusión, volúmenes y tiempo de duración de campos de lava diferentes, la longitud máxima ha sido similar (Guest et al., 1987). Si utilizamos una distancia máxima de $7 \mathrm{~km}$ para el campo de lavas Occidental, una tasa de efusión plausible para coladas basálticas del tipo aa, sería de unos 7 $\mathrm{m}^{3} / \mathrm{s}$ (Kilburn, 2000), aunque en el presente trabajo se toma un valor inferior por ser lavas porfiríticas calco-alcalinas (Cuadro 1).

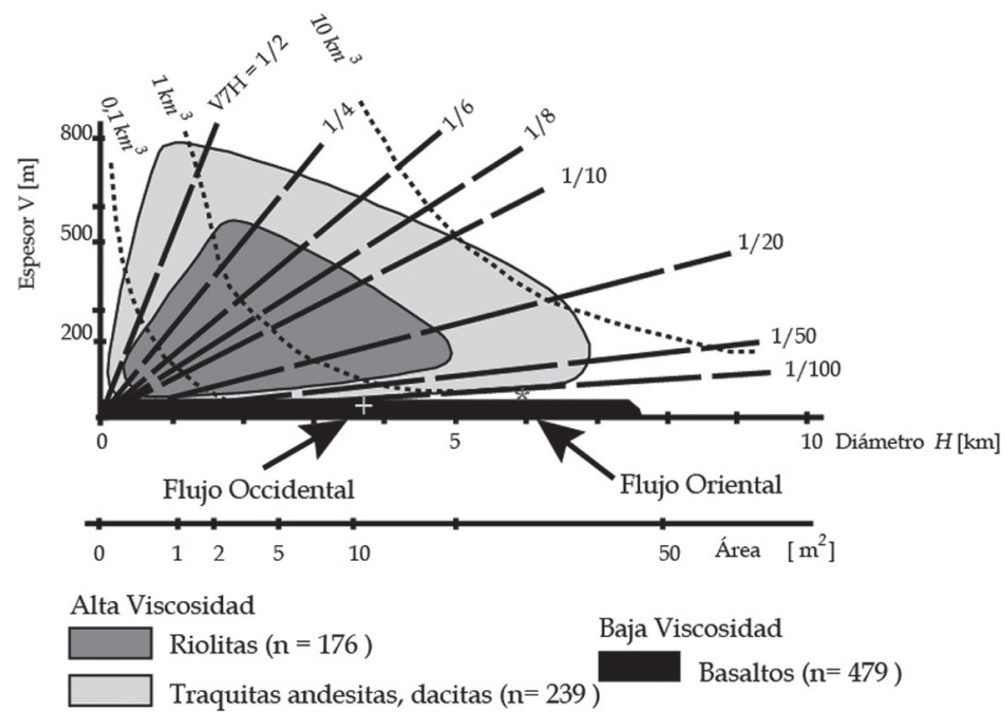

Fig. 11: Gráfico del espesor individual (2-4 m para la Occidental y unos 5-20 m Oriental, respectivamente) de las coladas de ambos campos de lava versus el área total (km2) de cada campo, y el diámetro del círculo imaginario que las representa (sensu Walker, 1973). 
Los campos de lava del Arenal constituyen nuestro mejor ejemplo de un estratovolcán con coladas andesítico basálticas aa en su cumbre, transición a blocosas (las predominantes), que eruptó coladas por más de 41 años (entre 1968 y finales del 2010), con gran variabilidad en los espesores acumulados y un área de cobertura relativamente importante. En Arenal, a partir de dos focos eruptivos, se desarrolló entre 1968 y 1974 un campo de lavas Inferior (cráter A) y entre 1975 y finales del 2010 un campo de lava Superior (cráter C). El campo Inferior posee espesores acumulados significativamente mayores de hasta $170 \mathrm{~m}$, y su tasa de efusión fue también más alta, mientras que el campo de lavas Superior fue relativamente más pequeño, con coladas cortas y menos espesas, y una tasa de efusión inferior (Borgia et al., 1998; Borgia \& Linneman, 1990; Wadge et al., 2006).

Thomas (1983) razonablemente piensa que no pudo solo haber habido un único foco eruptivo para cada campo de lavas en Cervantes, porque el tiempo de erupción habría sido de muchos años; entre 21,9 y 111,8 años para el campo de lava Occidental, por ejemplo. Efectivamente, para Cervantes se proponen dos sistemas de fisuras en par conjugado, conformados de varios focos eruptivos, de unos $2 \mathrm{~km}$ de longitud cada uno. La colada de Cervantes, al igual que en el Arenal, es la sumatoria de unidades de lava diferentes, para conformar lavas compuestas y al menos dos campos de lava, aunque en realidad la de Cervantes podrían ser más campos de lava dado que al parecer fueron varios los focos eruptivos. Por otro lado, para Kilburn (2000), la presencia de un túnel de lava en una colada de tipo aa (en nuestro caso es una variedad de aa, la de escombros escoriáceos) suele ocurrir en erupciones efusivas de larga duración. Con base en todo lo anterior, se podrían comparar los campos de lava históricos del Arenal (similares en morfología y petroquímica) con Cervantes y realizar una cruda estimación del tiempo que requirió para generar ambos campos, tomando en cuenta tasas de efusión similares tanto a las del Arenal como a algunas del Etna, Italia, para el caso de los basaltos (ver Cuadro 1).

\section{Volcano-tectónica}

Desde hace tiempo es conocido que el flanco sur del Irazú posee una serie de conos y cráteres parásitos o satelitales. Entre ellos, los más conocidos son el cono Pasquí, Gurdián y Noche Buena, y los cráteres de Quemados (Sáenz, 1971; Thomas, 1983, Alvarado, 1993). Sin embargo, una perforación realizada por el ICE en el cerro Gurdián (Fig.1) en 1993 indica que los primeros $12 \mathrm{~m}$ corresponden a cenizas finas a medias, pardo-negruzcas a gris, con fragmentos de lavas, bajo las cuales se presentan tres coladas de lava alteradas y fracturadas, con una potencia de al menos $78 \mathrm{~m}$ en

Cuadro 1

Comparación entre los campos de lava de Cervantes con los históricos del volcán Arenal. Entre paréntesis, el tiempo promedio y más probable

\begin{tabular}{|c|c|c|c|c|c|c|c|c|}
\hline $\begin{array}{c}\text { Campo de } \\
\text { lavas }\end{array}$ & $\begin{array}{l}\text { Altura foco eruptivo } \\
(\mathrm{m})\end{array}$ & $\begin{array}{l}\text { Aérea } \\
\left(\mathrm{km}^{2}\right)\end{array}$ & $\begin{array}{c}\text { Espesor } \\
\text { máximo }(\mathrm{m})\end{array}$ & $\begin{array}{l}\text { Longitud } \\
(\mathrm{km})\end{array}$ & $\begin{array}{l}\text { Volumen } \\
\left(\mathrm{km}^{3}\right)\end{array}$ & $\begin{array}{l}\mathrm{SiO}_{2} \\
(\%)\end{array}$ & $\begin{array}{c}\text { Tasa de } \\
\text { efusión }\left(\mathrm{m}^{3} / \mathrm{s}\right)\end{array}$ & $\begin{array}{c}\text { Tiempo } \\
\text { (años) }\end{array}$ \\
\hline $\begin{array}{l}\text { Arenal } \\
\text { Inferior }\end{array}$ & 1060 & 1,6 & $\sim 170$ & 3,5 & $\sim 0,28$ & $\begin{array}{l}54,2- \\
56,4\end{array}$ & $\sim 0,9-2,0$ & 4,9 \\
\hline $\begin{array}{l}\text { Arenal } \\
\text { Superior }\end{array}$ & $1460-1755$ & 5,5 & $\sim 70$ & 2,7 & $\sim 0,4$ & $\begin{array}{l}54,5- \\
56,0\end{array}$ & $0,1-0,49$ & 36,7 \\
\hline Cervantes E & $2000-2400$ & 28,14 & $\sim 150$ & 11 & $\sim 0,88-1,39$ & $\begin{array}{c}55,54- \\
56,58\end{array}$ & $\sim 0,5-2,0$ & $\begin{array}{c}13,9-88 \\
(45)\end{array}$ \\
\hline Cervantes W & $2500-2700$ & 10,85 & $\sim 20$ & 7 & $\sim 0,17-0,19$ & $\begin{array}{c}50,71- \\
53,42\end{array}$ & $\sim 0,5-5,0$ & $\begin{array}{c}1,0-10,8 \\
(6,7)\end{array}$ \\
\hline
\end{tabular}




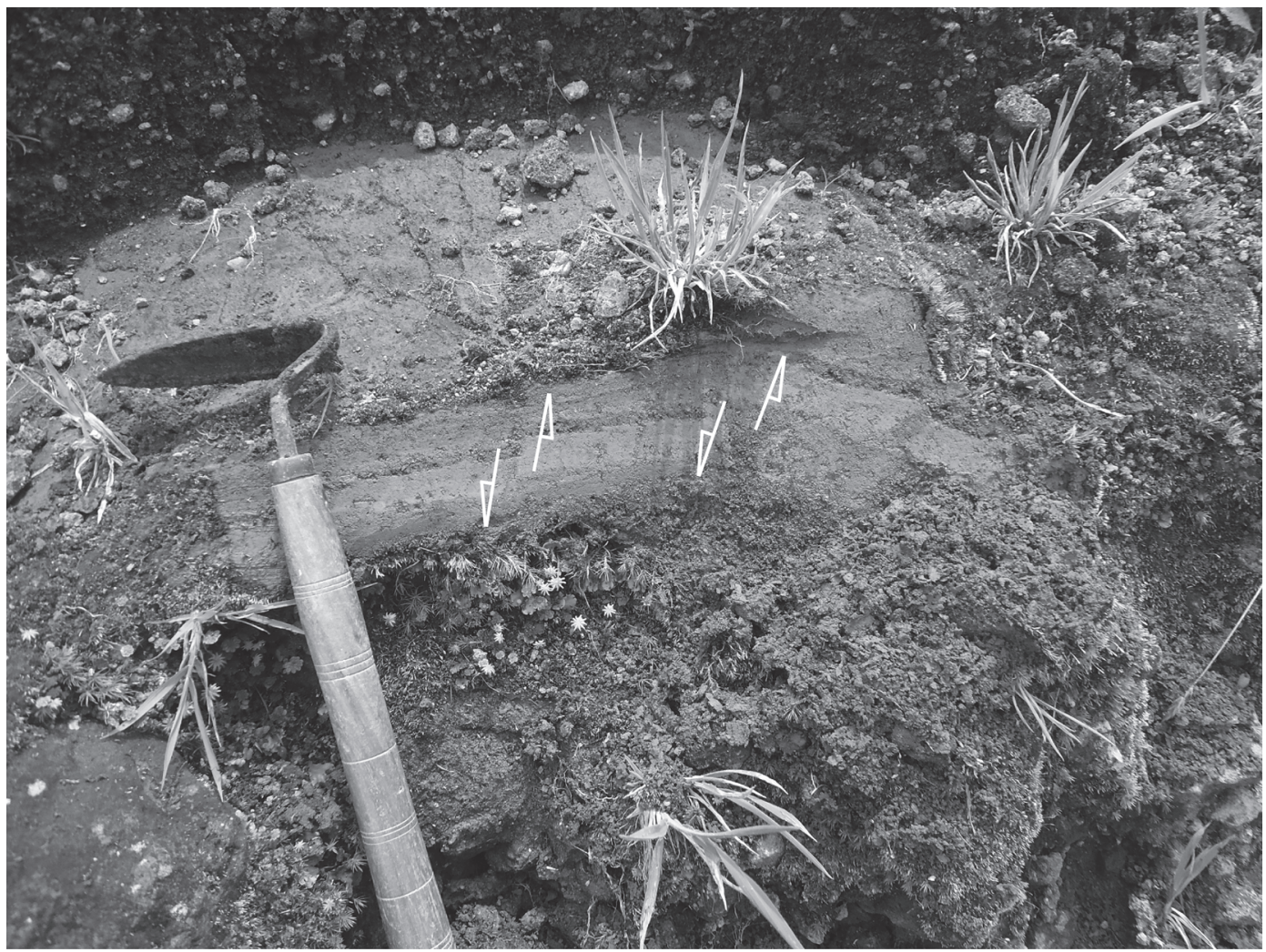

Fig. 12: Microfallas en la localidad de Santa Rosa, posiblemente sin-eruptivas, dado que afectan a las tefras posiblemente asociadas con el cono Pasquí.

total, puesto que la base de la colada inferior no se alcanzó (G.J. Soto, com. escrita, 1993). Pese a ello, no se presentan bombas ni lapilli escoriáceos, tal y como se esperaría en el caso de corresponder con un cono de escorias, similares al Pasquí o a los Quemados. Los cortes de carretera también muestran que los primeros $5 \mathrm{~m}$ corresponden con cenizas distales procedentes de la cima del Irazú. Para ello, el Gurdián parece corresponder con una morfología de falla.

Desde el punto de vista estructural, dos fisuras dieron origen a los campos de lava. El Oriental se generó a partir de una fisura con rumbo $\mathrm{N} 34^{\circ} \mathrm{E}$, mientras que el Occidental a partir de otra de rumbo $\mathrm{N} 26^{\circ} \mathrm{W}$. En las fotografías aéreas y en la imagen de radar, se observa claramente varios alineamientos interpretados como fallas, que se extienden a lo largo de 3-4 $\mathrm{km}$ de longitud con un rumbo $\mathrm{N} 20^{\circ}-28^{\circ} \mathrm{E}$. De igual modo, al norte de la localidad de Santa Rosa se observan microfallas del tipo normal, con rumbo $\mathrm{N} 10^{\circ} \mathrm{E}$ (Fig. 12), dirección similar a la orientación de los cráteres que fueron la fuente de origen del campo Occidental. Ya Olson \& Sáenz (1966) habían determinado una posible falla de $5,5 \mathrm{~km}$ de longitud y rumbo N15․ Hudnut (1983) reporta unos diques en la cumbre Sapper con un rumbo $\mathrm{N} 12^{\circ} \mathrm{W}$.

Así tenemos que el flanco sur del Irazú está atravesado por un sistema de fallas de rumbo $\mathrm{N} 26^{\circ} \mathrm{W}$ yN $20^{\circ}-28^{\circ} \mathrm{E}$, las cuales representan el par conjugado $\left(\sigma 1\right.$ estar orientado $\left.\mathrm{N} 4^{\circ} \mathrm{E}\right)$, favoreciendo el sistema fisural. Claramente, estas dos tendencias estructurales representan zonas de debilidad estructural, y por ello, sectores potenciales para la generación de nuevos conos satélites y para la efusión de coladas de lava. 


\section{Geoturismo}

La campiña de Cervantes es conocida por su belleza y restaurantes tradicionales de comidas típicas. Sin embargo, toda la zona alberga lugares que podrían constituirse en una ruta geoturística que se inicie en los hermosos cráteres de Quemados rodeando el cono Pasquí, continuando hacia el cráter Santa Rosa, y quizás el único túnel de lava hasta la fecha demostrado en Costa Rica, ubicado en Oratorio, para terminar con los lugares tradicionales de Cervantes, la represa de Cachí, el valle de Ujarrás, y la catarata de Los Novios.

\section{AGRADECIMIENTOS}

Varias personas nos acompañaron a las giras al campo, entre ellos M. Mora, C. Redondo, S.M. Garro, R. Ramírez y M. Pöhle. L. Esquivel y K. Pocasangre de la CNE y la RSN colaboraron con algunas de las giras al campo. Delimoa Orama Dorta y Pablo Herrera tuvieron la delicadeza de revisar el presente trabajo y aportar comentarios que lo enriquecieron substancialmente.

\section{REFERENCIAS}

ALLĖGRE, C.J. \& CONDOMINES, M., 1976: Fine chronology of volcanic processes using ${ }^{238} \mathrm{U}-{ }^{230} \mathrm{Th}$ systematics.- Earth and Planetary Sci. Letters, 28: 395-406.

ALVARADO, G.E., 1990. Los relieves de las rocas ígneas: Génesis, clasificación y aplicabilidad.- 167 págs. Ed. Tecnológica de Costa Rica, Cartago.

ALVARADO, G.E., 1993.Volcanology and Petrology of Irazú Volcano, Costa Rica.261 págs. Univ. Kiel, Alemania [Tesis Ph.D.].

ALVARADO, G.E., 2011. Los volcanes de Costa Rica: Geología, historia, riqueza natural y su gente ( $3^{\mathrm{a}}$ ed., $1^{\text {a }}$ re-impresión).-xxviii + 335 págs. EUNED; San José.
ALVARADO, G.E., CÁRDENES, G., ALVARADO, F., MURILLO, J. \& ARIAS, M., 2002: Utilización de rocas ornamentales en Costa Rica desde tiempos precolombinos hasta el siglo XX.- Rev. Geol. Amér. Central, 26: 39-51.

ALVARADO, G.E., VEGA, E., CHAVES, J. \& VÁZQUEZ, M., 2004: Los grandes deslizamientos (volcánicos y no volcánicos) de tipo debris avalanche en Costa Rica.- Rev. Geol. Amér. Central, 30: 83-99.

ALVARADO, G.E., CARR, M.J., TURRIN, B.D., SWISHER, C., SCHMINCKE, H.-U. \& HUDNUT, K.W., 2006: Recent volcanic history of Irazú volcano, Costa Rica: Alternation and mixing of two magma batches, implying at least two intracrustal chambers.- En: W.I. ROSE, G.J.S. BLUTH, M.J. CARR, J. EWERT, L.C. PATINO, and J. VALLANCE (eds): Natural Hazards in Central America. Geol. Soc.Am.Spec.Paper. 412: 259-276, doi: 10.1130/2006.2412(14)

BORGIA, A. \& LINNEMAN, S.R., 1990: On the Mechanisms of Lava Flow Emplacement and Volcano Growth: Arenal, Costa Rica.En: FINK, J.H. (ed.). Lava Flows and Domes. Emplacement Mechanisms and Hazards Implications.- IAVCEI Proceed. Volcanol., Springer-Verlag, Berlín: 208243.

BORGIA, A., POORE, C., CARR, M.J., MELSON, W.G. \& ALVARADO, G.E., 1988. Stratigraphic, structural and petrological aspects of Arenal-Chato Volcanic System, Costa Rica: Evolution of a young stratovolcanic complex.- Bull. Volcanol. 50: 86-105.

CASTRUCCIO, A., RUST, A.C. \& SPARKS, R.S.J., 2013: Evolution of crust- and core-dominated lava flows using scaling analysis.- Bull. Volcanol. 75: 681, DOI 10.1007/s 00445-012-0681-2. 
DÓNDOLI, C. \& TORRES, J.A., 1954. Estudio Geoagranómico de la Región Oriental de la Meseta Central.- 180 págs. Ministerio Agricultura e Industrias, San José.

GUEST, J.E., KILBURN, C.R.J., PINKERTON, H. \& DUNCAN, A.M., 1987: The evolution of lava flow-fields: observations of the 1981 and 1983 eruptions of Mount Etna, Sicily.- Bull. Volcanol. 49: 527-540.

HUDNUT, K.,1983: Geophysical Survery of Irazú Volcano.- 93 págs. Dartmouth College, Hanover [Tesis Bs.].

KILBURN, C.R.J., 2000: Lava flows and flow fields.- En: SIGURDSSON, H. (ed.): Encyclopedia of Volcanoes, Academic Press, San Diego: 291-305.

KILBURN, C.R.J. \& LOPES, R.M.C., 1991: General Patterns of Flow Growth: Aa and Blocky Lavas.- J. Geophys. Res., 96 (B12): 19 721-19 732.

KRUSCHENKY, R.D., 1972: Geology of Istarú Quadrangle.- 46 págs. U.S. Geol. Survey, Bull, 1358, Washington D.C.

KUSSMAUL, S., DE LEMOS, R., LAGUNA, J., AGUILAR, T. \& HERNÁNDEZ, S., 1994: Mapa de Recursos Minerales y Fósiles de la Gran Área Metropolitana.En: KUSSMAUL, S \& DENYER, P. (eds.): Atlas Geológico Gran Área Metropolitana, Editorial Tecnológica de Costa Rica.

MARR, W., 1863: Reise nach Central-Amerika.xvi +472 págs. Trad. al español: Viaje a Centroamérica, 2004). Ed. Univ. Costa Rica.

MACDONALD, G.A, 1972: Volcanoes.- xii + 510 págs. Prentice-Hall, Inc., Englewood Cliffs, New Jersey.

MADRIGAL, R., 1977.Geomorfología G-316.- 238 págs. UCR, San José. [folleto de curso].
MADRIGAL, R. \& ROJAS, E., 1980: Manual descriptivo del Mapa Geomorfológico de Costa Rica (escala 1: 200 000).- 79 págs, SEPSA, Imprenta Nacional, San José.

MURATA, J.J., DONDOLI, C. \& SAENZ, R., 1966: The 1963-65 eruption of Irazú volcano, Costa Rica (The period of March 1963 to October 1964).- Bull. Volcanol. 29: 765-796.

OLSON, C \& SÁENZ, R., 1966: Fotointerpretación de la colada de Cervantes, Costa Rica.- Inf. Semestral, julio-dic.1965, Inst. Geogr. Nacional, mayo 1966, San José: 23-37.

PINKERTON, H. \& WILSON, L., 1994: Factors controlling the lengths of cannel-fed lava flows.- Bull. Volcanol. 56: 108-120.

PINKERTON, H. \& NORTON, G., 1995 Rheological properties of basaltic lavas at sub-liquidus temperature: laboratory and field measurements on lavas from Mount Etna.- J. Volcanol. Geotherm. Res. 68: 307-323.

RITTMANN,A., 1960: Vulkane und ihre Tätigkeit ( $2^{a}$ ed.).- Trad. francesa (TAZZIEFF, H.): Les volcans et leur activité.- 461 págs. Masson, París.

SÁENZ, R., 1971: Aparatos volcánicos y fuentes termales de Costa Rica.- Inf. Técnico y Notas Geológicas, Dirección de Geologia, Minas y Petróleo, 41: 1-16.

SALAZAR, G. \& MADRIGAL, R., 1994: Unidades Geomorfológicas y su relación directa con la litología.- En: KUSSMAUL, S \& DENYER, P., 1994 (eds.): Atlas Geológico Gran Área Metropolitana, Ed. Tecnológica de Costa Rica, Cartago: 111-129.

TAKAGI, D. \& HUPPERT, H.E., 2010: Initial advance of long lava flows in open channels.J. Volcanol. Geotherm. Res. 195: 121-126. 
TOURNON, J., 1984: Magmatismes du Mesozoique a l' actual en Amerique Centrale: L'exemple de Costa Rica, Des ophiolites aux andesites.- 335 págs. Universite Pierre et Marie Curie, Paris [Tesis Ph.D.].

THOMAS, K., 1983: An Investigation of the Cervantes Formation at Irazú Volcano, Costa Rica.- 29 págs. Dartmouth College, Hanover [Tesis Bs.].

UMAÑA, E, 1962: Informe Geológico Preliminar del Proyecto de Cachí.- 36 págs. Div. Desarrollo, Instituto Costarricense de Electricidad, San José [Inf. Interno].

UMAÑA, J.E. \& ALFONSO, P.S: 1969: Confección corteza de impermeabilización en lavas cuaternarias de la margen izquierda de la ampliación del proyecto de Cachí.- 91 págs. + lámina. Oficina de Geología, Inst. Costarricense de Electricidad, San José [Inf. Interno].

WADGE, G., 1978: Effusion rate and the shape of aa lava flow-field on Mount Etna.Geology, 6: 503-506.

WADGE, G., ORAMAS DORTA, D. \& COLE, P.D., 2006: The magma budget of Volcán Arenal, Costa Rica from 1980 to 2004.- J. Volcanol. Geotherm. Res. 157 60-74

WALKER, G.P.L., 1973: Lengths of lava flows.Phil. Trans. R. Soc. London, 274:107-118.

WILLIAMS, H., 1952. Volcanic History of the Meseta Central Occidental, Costa Rica.- Univ. Calif. Publ. Geol. Sciences, 29(4): 145-179. 